\title{
A Polícia e suas Polícias: Clientela, Hierarquia, Soldado e Bandido
}

\author{
Erika Ferreira de Azevedo \\ Escola Britânica de São Paulo.
}

Resumo: A polícia militar representa um braço do Estado e apresenta-se para a população de forma contundente, ostensiva e, por vezes, brutal, não só para a sociedade como para ela mesma. Através da Análise Institucional do Discurso, a pesquisa aqui relatada teve como objetivo estudar os efeitos de reconhecimento e desconhecimento das relações no trabalho que permeiam o discurso de soldados da polícia militar: como estes falam de seu trabalho e, através desta fala, posicionam-se e posicionam sua clientela, sua hierarquia, seu objeto de trabalho (os "bandidos") e eles próprios. Buscou-se também analisar que lugar a violência ocupou neste discurso. Dez soldados da polícia militar do Estado de São Paulo foram entrevistados e a transcrição destas estrevistas foi analisada. A partir das análises, é possível refletir sobre a dubiedade do verdadeiro objetivo do trabalho policial, deslizando facilmente do cuidado da população desamparada ao cuidado de si, desamparado sob a pressão da farda.

Palavras-chave: Polícia; Instituição; Discurso; Sujeito.

\section{The Police and its Polices: Customers, Hierarchy, Soldier and Criminal}

\begin{abstract}
The Military Police represents an armed extension of the State. It presents itself to the population (and to itself) in an overwhelming, ostensive and sometimes brutal way. Through the Institutional Analyses of Discourse, this research aims at studying the effects of recognition and ignorance of work relationships that permeate the discourse of military police soldiers: how they talk about their work and how they position themselves and position the customers, the hierarchy and the object of their work (the criminals). We also looked into the place violence occupied in this discourse. Ten soldiers from the military police in Sao Paulo were interviewed and these were transcribed and analyzed. From the analyses, it is possible to reflect upon the ambiguity of the true object of police work, and on how it falls easily from the care of the population in need of protection to the soldiers' own protection, helpless under the uniform's pressure.
\end{abstract}

Keywords: Police; Institution; Discourse; Individual. 


\title{
La Policía y sus Policías: Clientela, Jerarquía, Soldado y Delincuente
}

\begin{abstract}
Resumen: La policía militar es un órgano del estado que se presenta para la población de forma contundente, prepotente y algunas veces con brutalidad tanto para la sociedad como para sí misma. Por medio del Análisis Institucional del Discurso, la siguiente investigación tiene como objetivo estudiar los efectos del reconocimiento y desconocimiento de las relaciones que caracterizan el discurso de los soldados de la policía militar: cómo hablan de su trabajo y, a través de estas conversaciones, cómo se posicionan e influencian a sus clientes; cómo es su jerarquía, su objetivo de trabajo (los delincuentes) y cómo se ven a sí mismos. Se pretendió también analizar cuál fue el lugar ocupado por la violencia en este discurso. Diez soldados de la policía militar del estado de Sao Paulo fueron entrevistados y la transcripción de estas entrevistas fue estudiada. A partir de estos análisis es posible reflexionar sobre la ambigüedad del verdadero objetivo del trabajo policial, desplazándose fácilmente del cuidado a la población al cuidado propio, desamparado bajo la presión del uniforme militar.
\end{abstract}

Palabras clave: Policía; Institución; Discurso; Sujeto.

\section{Introdução}

Em sua origem, tanto grega (politeia) quanto latina (politia), a palavra "polícia" carrega o sentido de governo. Ao longo do tempo, de fato, polícia veio representar a ação do governo para a manutenção da ordem e em proteção dos indivíduos. Desde seu início no Brasil, a polícia sofreu mudanças até configurar-se hoje, como legítima representante do Estado no que diz respeito à manutenção da ordem jurídica e pública com a função de garantir a tranquilidade e a proteção da sociedade (São Paulo (Estado), 2011a).

Em 1809, um ano depois da chegada da Família Real ao Rio de Janeiro, ocorre um fato importante para a origem da polícia militar estadual como temos hoje. Neste ano, é criada a Guarda Real que, desde aquela época, já refletia um modelo militar de polícia, subordinada ao Ministério da Justiça que se colocava não só como mantenedora da ordem, mas também como a serviço e à disposição do Estado. Ao passar dos anos, com a consolidação do Império em 1831, é feita a extinção dos diversos "corpos policiais existentes" para a criação de basicamente dois: o Corpo de Guardas Municipais Permanentes e a Guarda Nacional como complementares um do outro. Em ambos os casos, nota-se que os membros eram oriundos das classes dominantes - homens de posses que podiam votar (Ribeiro, 2011).

Ao analisar a trajetória histórica das polícias militares no Brasil, podemos perceber que por princípio as forças policiais estão vinculadas à manutenção da ordem, isso em alguns momentos da história do Brasil conduz as forças policiais a servirem para a sustentação do sistema político, muitas vezes defendido pelas oligarquias (Ribeiro, 2011, p. 10).

Este fato pode ser notado nos dias de hoje na relação da polícia, como instituição e através de seus atores, com a sua clientela, como veremos adiante na análise dos discursos produzidos.

Contudo, esta polícia, da garantia de tranquilidade e da proteção da sociedade e manutenção da ordem jurídica e pública, é também agente de atos de violência contra o cidadão e violações dos direitos humanos. Segundo dados (consulta atualizada em 2013) obtidos através do Banco de Dados do site do Núcleo de Estudos da Violência (NEV) da Universidade de São Paulo (USP) (2013), só no primeiro semestre de 2010 no estado de São Paulo, foram 86 casos de violência policial, sendo consequência destes, 129 vítimas, das quais 68 foram fatais. Ainda segundo a mesma fonte, no primeiro semestre de 2011, as Rondas Ostensivas Tobias Aguiar (ROTA) foram protagonistas de cinco notícias de jornais em São Paulo nas quais sua atuação resultou na morte de nove "suspeitos" de algum crime (roubo em quatro das histórias e tráfico de drogas em uma) em supostas "trocas de tiro" com os "bandidos".

Também é importante reconhecer que em 2012, de acordo com o jornal O Estado de São Paulo (Estado de São Paulo, 2012), 106 policiais militares foram mor- 
tos no estado. A maioria das mortes ocorreu, contudo, quando os policiais militares estavam em suas folgas; até o momento, não houve resposta pública sobre a solução destes casos.

Em prefácio para a terceira edição do livro "Direitos Humanos: coisa de polícia”, do educador Ricardo Balestreri (2003), secretário nacional de segurança pública no governo Lula, o então secretário nacional de segurança pública, Luiz Eduardo Soares reconhece que, desde a promulgação da Constituição de 1988, há uma dicotomia entre "os militantes dos direitos humanos e aqueles que clamavam por eficiência policial no combate ao crime" (Balestreri, 2003, p. 9). Segundo ele, essa "eficiência policial" dá licença para matar aos policiais, uma herança clara da época da ditadura, e acaba "produzindo o oposto do que tencionam: a impotência da segurança pública no controle da criminalidade, o aumento da impunidade, a debilidade institucional e a corrosão da imagem dos profissionais, destruindo-lhes a credibilidade" (idem). Para Balestreri (2003):

(...) A mera denúncia [dos abusos da polícia] tem um caráter excessivamente pontual, circunscrito ao episódio e ao momento histórico em que é feita. Ajuda no fato, mas não modifica profundamente os comportamentos pessoais e institucionais e, menos ainda, transforma os valores e as atitudes. Se queremos, um dia, viver uma verdadeira 'cultura de cidadania e direitos humanos', precisamos ir além da acusação, somando esforços pela construção de um novo modelo de segurança pública (p. 17).

Com estas considerações iniciais, podemos pensar numa polícia que representa um braço do Estado, presente na vida da população de forma contundente, ostensiva e, por vezes, brutal, para a sociedade e para ela mesma. Mas, quem são os soldados que fazem esta polícia militar?

\section{Revisão bibliográfica}

Quando a palavra-chave "polícia" é lançada no banco de teses do site da USP (busca realizada em 2012), o resultado é aproximadamente 4.650 itens entre dissertações de mestrado, teses de doutorado e livre-docência defendidas nesta universidade. Entre estes, há inúmeras duplicações. Nos trabalhos originais, o tema polícia aparece, muitas vezes, como referência indireta - certa instituição com "poder de polícia" - ou como referência de dados para outro tema - "segundo dados da polícia" - ou pesquisada de formas variadas: com relação a crimes de tipos específico (contra mulher, racismo etc.), do ponto de vista dos civis (ouvidorias, moradores de áreas mais pobre da cidade), das observações de sua atuação (letais ou não), de seu treinamento, entrevistas sobre serviços a eles prestados (plantão psicológico). Os mais relevantes para o objetivo da pesquisa aqui relatada foram os trabalhos de Luciano $(2007 ; 2011)$, voltada, em suas pesquisas de mestrado e doutorado, para a observação da abordagem do policial militar e seu treinamento, e o de Almeida (2010), com uma tese "histórica" sobre os movimentos reivindicatórios da polícia militar em 1997. Não é por acaso ${ }^{1}$ que estes trabalhos acadêmicos, como a maioria dos encontrados, tenham sido defendidos na Faculdade de Filosofia, Letras e Ciências Humanas.

A Psicologia é ainda tímida nas pesquisas sobre a polícia. Não há muitos trabalhos da pós-graduação em Psicologia sobre o tema. Dentro dos trabalhos de pós-graduação encontrados, destacamos como relevantes para nosso recorte: Spode (2004) e Bicalho (2005) que realizaram estudos acerca da subjetividade do policial militar. Spode versou, entre outras coisas, sobre a produção de subjetividade de um grupo de policiais e sua relação com o papel que ocupam. Bicalho apoiou-se no estudo da produção de subjetividade para examinar o conceito de Direitos Humanos de policiais militares em sua pesquisa-intervenção norteada pelos conceitos dos filósofos Gilles Deleuze e Félix Guatarri. Aqui, Bicalho faz uso de uma Análise Institucional para examinar o material aproveitado de um curso direcionado a policiais cujo objetivo é abordagem policial. Ele procura defender a tese de que "a lei não garante a prática porque direitos humanos e abordagem policial estão comprometidos com questões advindas do campo da produção de subjetividade" (do resumo). Alegretti (2006) estudou o que chamou de "resposta agressiva" do policial em ocorrências graves envolvendo o confronto armado ou

${ }^{1}$ Os dados do NEV, citados na introdução deste trabalho, associados aos comentários de autoridades no assunto, como o supracitado educador Balestreri, apontam para a existência de inúmeros conflitos sociais entre a polícia e a população como parte da realidade brasileira, portanto, seria esperado que as ciências sociais fossem as pioneiras em estudos que envolvessem a polícia como tema central. 
acidente com viaturas de policiais militares. Já Emílio (2011) estudou os efeitos de outros construtos institucionais na capacidade de resiliência de policiais militares de um batalhão do interior de São Paulo.

Do Instituto de Psicologia da USP, Faria (2000) defendeu sua dissertação de mestrado através de um "estudo exploratório" sobre o "profissional de segurança pública" e "o desempenho de seu papel num cenário estressante, de violência e de riscos" (extraído do título). As questões de pesquisa que são definidas para este trabalho consideram de saída - e o que se conclui não é diferente - que o profissional de segurança pública desempenha seu papel num ambiente tenso e violento, em que a sobrecarga emocional tem, entre outros efeitos, "comportamentos inadequados e de desajustamentos sociais tanto no contexto profissional como no social" evidenciando a necessidade, então, do 'provimento de suporto psicológico' por parte da própria 'instituição estado" (idem [do resumo])).

Em seu trabalho de doutorado, Faria (2006), então, procurou compreender o "papel do profissional de segurança pública e dos aspectos psicossociais que participam da formação de sua identidade profissional" (do resumo) e concluiu que, como já havia observado em sua dissertação de mestrado, o ambiente de trabalho do policial militar é um "cenário permeado por constantes mudanças, tensões, violência, confrontos sociais bem como perigos e riscos reais, em que o sujeito investido no papel absorve suas consequências físicas e emocionais” (idem) e há, então, por conta disto "...indícios de transtornos de personalidade antissocial em parte dos sujeitos (...) o que permitiu entrever um nível de gravidade no problema, maior do que inicialmente se presumia" (do resumo).

Também partindo do ponto de vista do sofrimento do sujeito, mas com um viés clínico - o atendimento de policiais militares em plantão psicológico -, Oliveira (2005) defendeu o mestrado com uma pesquisa que teve como questões norteadoras "o policial militar como sujeito social, o plantão psicológico e suas possibilidades de acolher o sofrimento, e a visão que o policial tem desse serviço" (p. 37). A partir de um recorte heideggeriano, considerando que "o sujeito humano, mesmo enquanto singularidade, não pode ser tomado fora de seu mundo, de seu contexto social (...). O homem é o que é apenas porque é no mundo" (p. 38), concluiu que, mesmo que alguns policiais militares não desejassem ser expostos pela participação no plantão psicológico como se a busca deste serviço mostrasse fraqueza" (p. 106), o policial militar é "carente de atenção” (p. 100) e, portanto, “(...) o plantão psicológico oferecido à PM [como instituição] demonstrou pertinência como forma de acolhimento ao sofrimento dos policiais em questão" [do resumo].

A busca por artigos científicos recentes no tema "polícia militar" nos apresenta as seguintes publicações: Souza e Reis (2014) realizaram um estudo dos estereótipos construídos pelo policial militar de Belém do Pará em suas abordagens de indivíduos "suspeitos" e verificaram que o padrão de abordagem policial "se desloca numa fronteira não claramente demarcada entre a obrigação legal de prover a segurança da sociedade" (p. 157). Cirilo (2013) versou sobre a espetacularização das atuações policiais na cidade do Rio de Janeiro concluindo numa análise que entrelaça as ideias de Foucault, Arendt e Debord que "O problema ainda está no fato de que 'salvar' a todos os que ali estão envolvidos não implica retirar da cena pública o velho jogo de quem deve ou não viver, que tipo de vida se considera válido, e o que é pior, querendo deixar sempre claro quem determina isso" (p. 24). Couto, Vandenberghe e Brito (2012) estudaram quais as relações interpessoais típicas de policiais alunos do curso de formação de oficiais de um estado brasileiro e como estas se relacionam com o estresse destes profissionais. Os resultados da pesquisa indicam que há a necessidade de medidas para o controle de estressores entre estes indivíduos, sobretudo dada a importância destes para as questões de segurança pública, tão caras e relevantes na sociedade brasileira atual. Faiad, Delabrida e Nascimento (2011) investigaram a satisfação da clientela em relação ao serviço prestado por policiais militares em Brasília, DF; Dantas, Brito, Rodrigues e Macientes (2010) pesquisaram o estresse em policiais militares de Minas Gerais concluindo, assim como Couto, Vandenberghe e Brito (2012), Oliveira (2005) e Faria (2006), que o nível de estresse é alto e estes profissionais carecem de atenção psicológica. E finalmente temos Derenusson e Jablonski (2010) estudando também a questão do estresse policial, mas do ponto de vista de como este afeta as famílias de policiais militares no Rio de Janeiro.

A intenção deste breve levantamento de dados não é quantitativa, mas qualitativa objetivando traçar um panorama das pesquisas realizadas acerca do policial militar para apresentar um recorte contextual onde o presente trabalho se insere e os discursos produzidos. Contudo, através deste levantamento, é possível verificar a veracidade do levantamento de Silva (2009) sobre "produção científica com temática relacionada à ativi- 
dade do policial militar" com especial atenção à "incidência de estudos cujo tema relaciona-se ao trabalho do policial como precipitador [sic] de sofrimento psíquico e implicações na saúde mental do trabalhador" quando ela conclui que "quando se analisa a produção científica formal e acessível à comunidade acadêmica (...) os resultados ainda são diminutos se comparados à relevância do tema" [do resumo].

Ademais, através deste levantamento de dados é possível notar, entretanto, que há um movimento das pesquisas acadêmicas em Psicologia no sentido de olhar para o policial militar como um indivíduo, para além da instituição; que este movimento parte de questões que relacionam o trabalho do policial com as questões da violência de um modo geral; com a novidade do acréscimo de considerações sobre o sofrimento emocional deste agente institucional e, apesar disto, ainda há poucas pesquisas no tema, sobretudo as que caracterizam as marcas da violência desse trabalho em relação à corporação, à população e ao próprio policial.

\section{Objetivo}

Orientada por uma proposta metodológica específica, a pesquisa aqui relatada teve como objetivo estudar os efeitos de reconhecimento e desconhecimento das relações no trabalho que permeiam o discurso de um grupo de soldados da polícia militar: como estes falam de seu trabalho e através desta fala posicionam-se e posicionam sua clientela, sua hierarquia, seu objeto de trabalho (os "bandidos") e eles próprios. Buscou-se também analisar que lugar a violência ocupou neste discurso. Não se trata de dar voz a ninguém, mas de, como disse Dominique Maingueneau em prefácio para o livro " A análise institucional do discurso como analítica da subjetividade", de Marlene Guirado (2010), ouvir a "ação que se exerce através da língua em situações definidas institucionalmente" (p. 17). Escutar a "fala" que preferem estas pessoas de dentro da prática institucional.

\section{Método}

O norte conceitual/metodológico é a Análise Institucional do Discurso, método de pesquisa em Psicologia desenvolvido por Marlene Guirado (2010), fruto de anos de entrecruzamentos com a psicanálise freudiana, as noções de sujeito, poder e discurso de Foucault, o conceito de instituição de Guilhon de Albuquerque e de discurso de Dominique Maingue- neau. Faremos algumas considerações metodológicas no que tange ao objetivo desta pesquisa. Vamos a elas.

A primeira coisa que se deve notar é que este não é um método que se aplica em pesquisa, mas é um norte que orienta seu fazer do começo ao fim tornando-se parte de seu contexto. É como se ele fosse renovado a cada pesquisa, renegociado com os elementos daquele grupo de pessoas, suas falas, seus lugares e os lugares atribuídos a quem $\mathrm{faz}$ a pesquisa. Assim, esta pesquisa insere-se num dispositivo metodológico, num certo modo de produzir... Psicologia chamada Análise Institucional do Discurso (Guirado, 2010).

Segundo Galvão e Serrano (2007):

A originalidade e a importância dessa abordagem teórica e metodológica para nossa área relaciona-se com uma perspectiva precisa de leitura institucional - isto é, uma compreensão da vida institucional como matriz de toda subjetividade articulada a uma concepção específica de análise e de discurso (p. 22).

Neste entrecruzamento conceitual, trabalhamos com as seguintes leituras de alguns conceitos:

Instituições como "práticas ou relações sociais que se repetem e se legitimam, na ação mesma de seus atores; são seus efeitos de reconhecimento e desconhecimento que dão o caráter de legitimidade, de naturalidade; ao que é instituído" (Guirado, 2010, p. 26), conceituação que torna possível aproximar a noção psicanalítica de transferência à sociologia de Guilhon Albuquerque em sua definição de objeto institucional como "as relações tal como percebidas, imaginadas, pelos que as fazem, concretamente" (Guirado, 2010, p.25). Da análise do discurso francesa, tomamos os conceitos de gênero de discurso, comunidade discursiva e cena enunciativa que nos permitem pensar a linguagem como discurso e, este, como ato de fala cujo sentido só se pode apreender pelo contexto em que se produz, pelo dispositivo social que o matricia assim como dialogado com Dominique Maingueneau (idem). Dos estudos de Foucault, "a concepção de discurso como ato, como instituição, que circula e que é, ao mesmo tempo, alvo de relações de poder [grifos nossos], e que se coloca como a maquinaria de produção de saber, de verdades e de subjetividades" (Guirado, 2010, p. 25-26).

Este método de pesquisa pretende produzir um sujeito atravessado por dobradiças conceituais acionadas por uma estratégia de análise do discurso 
(Ribeiro, 2007) que, portanto, não tem como não ser institucional. Um soldado policial militar que no seu discurso repete o discurso institucional e torna viva a instituição ao mesmo tempo em que expõe pedaços de si, atravessados na fala por estas histórias posicionando, ao mesmo tempo, a instituição de onde fala, quem fala e a quem fala. Faz isso não só através do que fala, mas tanto quanto através de como fala.

\section{Instituição em estudo}

O norte conceitual e metodológico, a Análise Institucional do Discurso, pressupõe uma instituição em estudo.

A instituição escolhida é a Polícia Militar do Estado de São Paulo (São Paulo (Estado), 2011a). Numa espécie de "autodescrição", a instituição se apresenta como um grupo de atores institucionais demarcados em seus papéis e posições, e assim nos convida a ensaiar uma análise como prelúdio às análises das entrevistas que foram objeto para as conclusões apresentadas aqui:

A Polícia Militar é hoje uma organização fardada, organizada militarmente, subordinada ao Governador do Estado, através da Secretaria de Segurança Pública e do Comando Geral da Corporação, e que presta seus serviços dentro do rigoroso cumprimento do dever legal.

Por ser um corpo militar, dispõem de meios e ferramentas para coibir excesso no seio da tropa, fatos esses a que nenhuma organização está imune, mas que, dada a reação draconiana aplicada aos infratores, inibe e desestimula atitudes antissociais. A maior prova disso é a correta apresentação das estatísticas pela Corporação, incluindo os desvios de seu pessoal e as punições sofridas pelos maus.

A tropa da Corporação tem contribuído com sua quota de sangue, perdendo pessoal em mortes e em casos de invalidez, enfrentando incompreensões e injustiças, lutando contra faltas de efetivo e, por vezes, de meios, mas tem deixado sua marca positiva nos corações dos paulistas que amam sua terra, que desejam um futuro melhor, e que comungam conosco do ideal de uma pátria grande e feliz (São Paulo (Estado), 2011b) [grifos nossos].

Ensaiemos. O que se apresenta neste discurso é um grupo "fardado, organizado", e "subordinado den- tro do rigoroso cumprimento do dever legal", que busca "coibir excesso" com "reação draconiana aplicada aos infratores" sendo a "maior prova" disto as "estatísticas" dos "desvios de seu pessoal e as punições sofridas pelos maus" ainda que tenha "contribuído" com sua "quota de sangue" e ache que tenha "enfrentado incompreensões e injustiças", embora acredite ter uma "marca positiva nos corações dos paulistas que amam sua terra" e que tem o mesmo "ideal de uma pátria grande e feliz".

Para o "rigoroso cumprimento do dever legal", a polícia militar é prescrita na Constituição Federal (Brasil, 1988) no Capítulo III, que trata sobre segurança pública:

Art. 144 - A segurança pública, dever do Estado, direito e responsabilidade de todos, é exercida para a preservação da ordem pública e da incolumidade das pessoas e do patrimônio, através dos seguintes órgãos:

I - polícia federal;

II - polícia rodoviária federal;

III - polícia ferroviária federal;

IV - policias civis;

$\mathrm{V}$ - policias militares e corpos de bombeiros militares.

[grifos nossos]

Dispõem sobre a polícia militar os parágrafos seguintes:

$\$ 5^{\circ}$ Às polícias militares cabem a polícia ostensiva e a preservação da ordem pública: aos corpos de bombeiros militares, além das atribuições definidas em lei, incumbe as atividades de defesa civil.

$\$ 6^{\circ}$ As policias militares e os corpos de bombeiros militares,forças auxiliares e reservas do Exército, subordinam-se, juntamente com as polícias civis, aos Governadores dos Estados, do Distrito Federal e dos Territórios [grifos nossos].

Sendo a segurança pública "dever do Estado", vejamos o que diz dela a Constituição do Estado de São Paulo (São Paulo (Estado), 1989):

Art. 139 - A segurança pública, dever do Estado, direito e responsabilidade de todos, é exercida para a preservação da ordem pública e incolumidade das pessoas e do patrimônio.

$\$ 1^{\circ}$ - O Estado manterá a Segurança Pública por meio de sua policia, subordinada ao Governador do Estado.

\footnotetext{
${ }^{2}$ Ainda que o objeto das análises não sejam textos oficiais propriamente ditos e que a autodescrição da instituição apresentada seja um recorte.
} 
$\$ 2^{\circ}$ - A polícia do Estado será integrada pela Polícia Civil, Polícia Militar e Corpo de Bombeiros.

$\$ 3^{\circ}$ - A Polícia Militar, integrada pelo Corpo de Bombeiros, é força auxiliar, reserva do Exército.

Art. 141 - À Polícia Militar, órgão permanente incumbe além das atribuições definidas em lei, a polícia ostensiva e a manutenção da ordem pública.

$\$ 2^{\circ}$ - Lei Orgânica e Estatuto disciplinarão a organização, o funcionamento, direitos, vantagens e regime de trabalho da Polícia Militar e de seus integrantes, servidores militares estaduais, respeitadas as leis federais concernentes [grifos nossos].

A repetição causa efeito de importância, que não seja esquecido, "à polícia militar cabe a polícia ostensiva e a manutenção da ordem e preservação da ordem pública e incolumidade das pessoas e do patrimônio" [grifos nossos].

Sobre sua organização, comenta Oliveira (2005):

A escala hierárquica da Polícia Militar obedece, em ordem ascendente, a seguinte configuração: soldado, cabo, terceiro sargento, segundo sargento, primeiro sargento, sub-tenente, segundo tenente, primeiro tenente, capitão, major, tenente coronel e coronel. A distribuição de autoridade revelada por esta escala permeia as relações que acontecem dentro da instituição em quase todos os momentos. $\mathrm{O}$ ato de "bater continência”, reverência obrigatória sempre que um policial militar encontrar outro de maior graduação (ou mais velho),é exemplo disso. Ao iniciar todo contato entre dois policiais de nível hierárquico diferente, a "continência” mostra que, nesta instituição, nenhuma relação pode sequer se iniciar sem que ambos expressem o reconhecimento e a aceitação da desigualdade hierárquica (nesse sentido, como uma observação advinda do próprio contato com os policiais militares, vale notar que o ato de continência é sempre iniciado pelo policial de nível hierárquico inferior) (pp. 56-57).

Esta foi a instituição estudada, num determinado nível, através de seus agentes que têm contato direto com a população - soldados - aqueles de nível hierárquico mais baixo.

\section{Procedimento}

Foram entrevistados dez soldados da PMSP de uma mesma Companhia - podendo-se concluir então que eram do mesmo Comando de Policiamento de Área ${ }^{3}$ e Batalhão. Foram nove homens e uma mulher, dois soldados do turno da noite e o restante da manhã (incluindo a única mulher). O discurso da única mulher foi mantido e analisado junto dos outros discursos sem uma análise específica para a questão de como a diferença de gênero poderia apresentar um viés nos discursos, pois o foco da análise das entrevistas foi a construção de um discurso institucional que, como mencionado no método, "torna viva a instituição". Assim, o objetivo da pesquisa não era analisar diferenças de gênero na produção do discurso, mas como o discurso dos atores de uma instituição poderiam, em seu entrecruzamento, refletir o discurso da corporação como um todo. Além disso, considerando que segundo dados do Instituto Brasileiro de Geografia e Estatística (IBGE) de 2015 (Globo.com, 2015), a presença de mulheres na corporação não chega a 10\%, a amostra de nove homens e uma mulher apresenta correta proporcionalidade entre os gêneros e, portanto, acurada representatividade. Isto não significa que não haja margem para que outras pesquisas procurem fazer a análise desta questão.

Cada indivíduo foi entrevistado individualmente em sala da corporação durante o expediente de trabalho através do aviso do capitão que "a psicóloga estava lá" e quem pudesse/quisesse, poderia vir dar entrevista. A psicóloga então se apresentava, a si e a pesquisa, aos potenciais entrevistados e estes escolhiam permanecer para a gravação ou não. Uma pessoa não quis dar entrevista e outras quatro não puderam fazê-lo por falta de tempo. A cada entrevistado foram feitas as mesmas questões-chave segundo roteiro abaixo:

a) Conte-me um dia de trabalho seu, desde a hora que você chega até a hora que você sai.

b) Conte-me alguma situação ou atividade, durante essa sua rotina, que você considera mais difícil ou mais complicada.

c) Conte-me alguma situação ou atividade, durante essa sua rotina, que você considera mais fácil ou menos complicada.

${ }^{3}$ Comando de Policiamento de Área da capital. “Os comandos de Policiamento estão divididos segundo as zonas da cidade (leste, oeste, centro, sul e norte), o que implica que tenham sob sua responsabilidade áreas bastante grandes e complexas. Para tornar viável a administração do policiamento de áreas tão extensas, os Comandos estão sub-divididos em Batalhões, e este, em Companhias" (Oliveira, 2005, p. 58). 
d) Conte-me alguma situação que considere mais característica do que é ser policial militar, do seu trabalho. Dê algum exemplo.

e) Conte-me a situação mais marcante que você já viveu como policial militar.

f) Há alguma influência externa no seu trabalho de policial militar?

g) Há alguma influência do seu trabalho de policial militar na sua vida fora daqui?

h) O que é ser policial militar pra você?

Outras perguntas, a título de esclarecer a questão da entrevistadora ou detalhar mais as respostas dos entrevistados, foram feitas. O primeiro entrevistado foi o único que não partilhou deste roteiro por ter feito parte de uma entrevista livre, sem roteiro pré-estabelecido, experimentalmente. Sua entrevista é mantida nas análises pelas seguintes razões: esta pesquisa não é quantitativa, ou seja, não se quer inventariar respostas específicas para determinadas perguntas e, mesmo não seguindo este roteiro, o tema de sua entrevista - assim como as outras variáveis envolvidas - é o mesmo dos outros entrevistados; logo, o discurso produzido nesta ocasião também pôde compor o discurso das análises.

O tempo de duração de cada entrevista variou por conta das características da interação entrevistadora-entrevistado no momento de cada entrevista, mas nenhuma pergunta deixou de ser feita e esclarecimentos foram feitos quando necessário.

Para configurar este sujeito soldado policial militar, foi analisado o discurso gravado e transcrito destas entrevistas. Esta análise baseou-se em uma reorganização discursiva que não se trata de "uma organização textual em si mesma", mas uma reorganização de falas que "associa uma organização textual e um lugar social determinado" (Charaudeau, \& Maingueneau, 2004, p. 44 citado por Guirado, 2010, p. 96).

Nesta mesma perspectiva metodológica, a entrevista é um gênero discursivo, um dispositivo que, como qualquer outra prática institucional, supõe uma correlação de forças na qual sujeitos posicionam-se e objetivam-se. Posto isto, a relação de/em entrevista, no discurso gravado e transcrito, também é ocasião de análise, embora não explicitamente. A fim de manter o princípio da transparência do método científico, é necessário mencionar que o fato da entrevistada ser uma mulher, nitidamente grávida e identificada como oriunda da Universidade de São Paulo eram lugares que também atravessaram a ocasião da entrevista e podem ter suscitado diferentes posicionamentos dos entrevistados, ainda que este dado em si não possa ter sido analisado visto a proposta da pesquisa incluir apenas uma pesquisadora em campo.

Esta ocasião de análise leva em conta os elementos presentes na cena enunciativa no momento da entrevista, ou seja, aquela entrevistadora, aquele entrevistado, as instituições que os atravessam, o espaço que ocupam, como ocupam e suas histórias individuais. Alguns elementos dignos de nota: o questionamento dos entrevistados no momento pré-entrevista sobre a que vinha e o que queria falar aquela estudante da USP, revelando uma preocupação com a opinião que entendiam que aquele grupo de pessoas ("uspianos") emitiam sobre a corporação. E as falas que colocavam a família, tanto a família em casa a espera do policial militar, quanto a família atendida pela polícia militar, considerada clientela desejável por sua suposta fragilidade (os doentes, velhos e grávidas). Como veremos adiante na análise que é feita do discurso desses policiais militares, no que tange à clientela, a entrevistadora, possivelmente, ocupava uma posição ambígua para eles: da clientela algoz, por ser da USP, mas também da clientela boa, por estar grávida. Como dito acima, ainda que não tenha sido objeto direto da análise, esses são elementos importantes para mostrar o contexto no qual a pesquisa foi realizada.

Sendo este discurso produto e produtor de uma prática institucional, não será, então, de se surpreender que haja tantas repetições temáticas e de modos de falar; "um jeito PM de falar". Estes sujeitos-dobradiça que falam "ao mesmo tempo dos autores das cenas enunciativas e das condições de enunciação" (Guirado citado por Galvão, \& Serrano, 2007, p. 29) só podem, de acordo com Ribeiro (2007), ter "a subjetividade... pensada numa chave analítica que inscreva, constitutivamente, práticas institucionais (p. 248)" e cujo acionamento se dá na e pela análise do discurso, buscando reconstruir os sentidos nesta rede discursiva que nos apresentam o sujeito que se desenha nesta relação entre natureza do texto e análise (Guirado, 2010).

O discurso é um ato no qual o sujeito é construído historicamente e na configuração da cena discursiva que é atravessada tanto pela história da instituição quanto do indivíduo. Não é transparente porque há um posicionamento do indivíduo, mas não é um sujeito escondido e encontrado; seu discurso não é interpretado, mas analisado institucionalmente no que mostra de seu fazer concreto. Não há caminhos traçados, mas negociados (Guirado, 2010). 
Esta análise do discurso, nos reconhecimentos e desconhecimentos mostrados em ato, configurou-se ao redor dos seguintes agrupamentos: a configuração da clientela; a forma como a hierarquia apareceu na fala; a posição do "bandido", e a condição de ser e estar policial que estas pessoas nos mostraram a partir disto.

\section{Análises}

Antes de comentarmos nossas análises, faremos um brevíssimo apanhado do que alguns dos outros trabalhos citados apontaram, tanto em aspectos descritivos como conclusivos, recortes que podem dialogar com nossas conclusões.

Sobre a relação com a clientela, Silva (2009) ecoa o discurso dos policiais militares desta pesquisa que, apesar dos "indícios fatuais de hostilidade entre 'civis' e 'militares', parece existir no imaginário popular uma apropriação automática de que, diante de um problema "chamem a polícia'" (p. 3). Oliveira (2005) também faz coro com Silva (2009) e os policiais entrevistados de que "via de regra, para o cidadão comum, o telefone da PM é um recurso que pode ser utilizado para qualquer tipo de emergência" (p. 69). Sobre a hierarquia, aponta Oliveira (2005) que "aquele que exerce a função de comando é sempre alguém que se encontra numa posição bastante privilegiada de poder" e que, assim, "a desigualdade de distribuição desse poder de mando entre os sujeitos sociais é fato notório". O que também nos lembraram aqui os dez soldados entrevistados. Faria (2006) aponta a importância da legalidade e das regras e procedimentos; Oliveira (2005) também aponta a variabilidade dos deveres e alterações constantes dos procedimentos como frequentes no trabalho dos policiais. Quase em uníssono com nossos entrevistados. Finalmente, sobre os riscos corridos em especial na relação com o “bandido”, Faria (2006) enfatiza a sensação maximizada de tensão em diversas situações de risco que são usadas como justificativa para respostas equivalentes dos soldados. Posicionamento repetido inúmeras vezes nas falas analisadas aqui.

Sem a intenção de resumir a amplitude do que estas pesquisas realizaram, podemos, entretanto, dizer que as temáticas repetidas não são novidades e não o são por acaso. Fazem parte de uma fala de indivíduos atravessados pela mesma instituição. Contudo, nos propomos não a repetir as temáticas; que elas venham porque inevitáveis o são, mas, no que o nosso recorte teórico metodológico pode fazer, nos propomos a analisar como falaram sobre isso tudo os policiais militares aqui entrevistados.

No que tange aos lugares ocupados pela clientela no discurso dos soldados da PMSP entrevistados nesta pesquisa, encontramos os seguintes lugares: da clientela boa e da clientela algoz; e do cliente ou do suspeito.

A clientela boa surgia como pessoas indiferenciadas. Nesta indiferenciação, as pessoas eram simplesmente ocorrência. Quando eram algo, eram despossuídas; faltava-lhes, segundo fala dos policiais militares, "um QI a mais", "um raciocínio", "esperança”, "caminhos". O caráter positivo desta clientela deu-se no fato de que eram estas que possibilitavam ao policial militar ocupar um lugar de salvador, de herói justamente por estarem nesta posição de preenchimento desta falta. A posição dessas pessoas ou na ignorância - não saber o que fazer - e no desamparo - precisar de alguma coisa - permitia ao policial militar uma ação e algo que para ele era "fácil" prover e, portanto, era fonte de satisfação para o policial militar. Esta era a parcela ideal da população que entendia, aceitava, respeitava e submetia-se - afinal de contas não tinha outro jeito - ao policial herói. Em alguns momentos, deu-se a impressão de que o policial militar "trabalhava para garantir isso", garantir o não saber e o desamparo e, assim, receber o agradecimento desmedido e o retorno esperado pelo seu trabalho: o respeito à farda.

Contudo, havia uma parte da clientela que transformava o policial militar em uma "vidraça" a ser atacada a "pedradas". O que desagrada nesta parcela é que ela não entende, não respeita, não se submete ao policial. Ela é a que, nesses relatos, é vista como a que, embora vá precisar (do policial militar), critica ao invés de ficar "superagradecida”. Com relação, justamente, a estas críticas, é interessante notar um movimento discursivo que faz o policial militar distanciar-se e diferenciar-se da mesma farda que o acompanhou nos momentos de clamar por respeito e submissão. Ele não nega os atos negativos da corporação que fazem esta clientela temer a polícia, mas com muita naturalidade se justifica; a população precisa, como um todo, ser policiada, corrigida, de voz ativa. A única pessoa errada é a que não entende a polícia, que critica e agora tem medo da polícia. A única coisa que pode mudar isso é a ação policial, mas não qualquer uma, ações direcionadas a quem está vulnerável segundo esta leitura da sua clientela.

Esta mesma população foi habilmente classificada para um tratamento "ao gosto do cliente". Numa mistura do lugar da polícia com o lugar da justiça, a clientela foi 
organizada entre os "suspeitos - que moram em comunidade", de onde, supôs-se poder esperar que venha o tiro, e os "desembargadores, ministros, advogados, promotores" ao mesmo tempo em que são os algozes que humilham-“vocêsabecomquemvocê estáfalando?"-corretamente avaliados e localizados garantem o bom resultado, o retorno desejado, o bom trabalho, o respeito à farda. A clientela fez a farda vestir um policial e um policialzinho. O vínculo com a farda, vestida ou escondida (para evitar o ataque previsto dos "suspeitos"), posicionou o olhar do policial militar para um mundo de mais ou menos riscos contra os quais se deve estar pronto para contra-atacar sempre. Acima de tudo, contra-atacar uma violência que emanava da própria clientela.

Na sua relação com a sua hierarquia, houve uma inversão de posições, na qual, em alguns momentos os policiais se aproximavam daquela posição que atribuíam à clientela e de outro aos criminosos.

O horário foi a primeira marca da hierarquia, posicionando o policial militar como regulado, normatizado, corrigido - mecanicamente como um relógio - para ficar igual aos outros. O mais importante era chegar na hora, era a única cobrança, repetida e enfatizada, chegar na hora, farda em ordem, barba feita, como os outros, para então seguir com as ordens do dia. No ritual pessoal, de preparo para ir ao trabalho, a marca institucional atravessa o policial militar que aqui vestiu a farda mesmo antes de chegar ao trabalho, quando esta ainda estava escondida na mala. $O$ peso desta regra era tal que soava como se fosse a única que houvesse e com caráter exclusivo para os policiais. De fato, ao longo dos relatos, regras e procedimentos emergiam, porém de maneira difusa, como se o próprio policial se fundisse com eles. Procedimentos que eram sempre contra ou a favor do policial, nunca só procedimento. Era como se se repetisse com a instituição a posição que os policiais atribuíam à clientela, o lugar de ser corrigido e de ser punido.

De um lado, as regras e procedimentos constituíam-se como forma de proteger o policial militar do erro e da consequente punição; de outro era a inexorável causa destes e, nesse movimento, a farda tornava-se a justificativa do erro e a forma de falar legitimamente das "más pessoas" de dentro da polícia sem se implicar. Não existia o erro, era "alguém de cima" que tinha que mudar algo ou que impunha algo, eram regras impossíveis de serem seguidas, cobrança desmedida ainda que invertida, regras que atrapalhavam o "serviço", o "trabalho" do policial militar. Nessa relação, o sol- dado colocava-se na corda bamba de poder, a qualquer momento, pender para ao lado "errado" e cometer um crime. E aproximar-se do "bandido", na medida em que tentava diferenciar-se. $\mathrm{O}$ bandido era aquele que não tinha regras a seguir, ou que não cumpria regra, como se houvesse um acordo silencioso que - na cabeça do policial militar - fizesse ele (o policial militar) esperar que o criminoso aceitasse as regras do jogo como as que ele (policial militar) estava submetido.

Pressupondo-se só na linha de frente, por conta desta sensação de desamparo institucional; conduta justificada, legitimada e reforçada pelo discurso que quase, aliás, indissocia bandido e clientela e o próprio policial militar, passa a ser naturalizado que o policial militar coloque-se no lugar de alvo e que a ajuda e proteção ao 'amigo de farda' torne-se legitimamente o foco de seu trabalho. $\mathrm{O}$ estressante do trabalho do policial militar residia justamente nesta inversão, quando o policial militar tornava-se alvo.

Novamente a questão da farda como símbolo deste tipo de posicionamento do policial aparece no discurso. Por conta da solitude no trabalho, do desamparo institucional, de ser alvo da clientela/bandido, ter que esconder a farda passa a ser o centro da "dificuldade" do policial militar em seu trabalho. Contudo, isto parece revelar que o desejo é de ostentar a farda, no sentido da polícia como "ostensiva" para fazer o trabalho do policial militar, inferindo que não é que o policial tenha que ser policial militar o tempo todo por uma questão naturalizada de vida ou de morte, mas que o policial quer ser policial militar o tempo todo, afinal de contas, na lógica construída na cabeça dele, ele pode não ter condições de ostentar sempre, mas precisa sempre vigiar.

\section{Conclusão}

No final das contas, a noção do ser tudo, de ser aquele que preenche as faltas da clientela, desliza para o cuidado da população despossuída e culmina com a proteção da vida do policial como foco último do trabalho do policial militar. Da obrigação como braço do estado, desliza-se naturalmente para a satisfação na forma do braço amigo e perdura, de fato, ao lado do amigo de farda.

A farda se sobrepõe ao indivíduo marcando com toda força a matriz institucional deste discurso. Ao falar-se tanto dela nas análises das entrevistas, não se trata de atribuir ao policial militar o lugar de vítima da farda, mas de apontar que a forma como cada policial fala de si, de seu trabalho e dos atores com quem contracena denota o caráter institucional do 
sujeito-policial. E a violência? Estes dez soldados não estão entre acusados de violência policial. O que responderiam às mesmas perguntas soldados oficialmente apontados (e punidos?) por atos de agressão contra a população? Contudo, não é por isso que esta questão tenha que ser descartada. Não só porque a instituição que convida a vestir a farda é a mesma. Mas sobretudo porque, deste lugar atravessado, a farda torna-se facil- mente um escudo para justificar os atos do indivíduo dando-lhes um efeito de inevitabilidade e necessidade. Em última instância, de ter de sair às ruas para se salvar e se defender. De um lugar que abre brechas para deslizar do "caminho da lei" para o "do crime". Para o caminho potencialmente da violência. Os mesmos lugares a partir dos quais podem sair às ruas qualquer soldado policial militar do Estado de São Paulo.

\section{Referências}

Alegretti, R. (2006). Estudo dos feitos de programa de apoio na agressividade reacional de policiais envolvidos em ocorrências graves (Dissertação de mestrado). Universidade Metodista de São Paulo, São Paulo, SP.

Almeida, J. R. (2010). Tropas em protesto: o ciclo de movimentos reivindicatórios dos policiais militares brasileiros no ano de 1997 (Tese de doutorado). Faculdade de Filosofia, Letras e Ciências Humanas, Universidade de São Paulo, SP.

Balestreri, R. B. (2003). Direitos humanos: coisa de polícia (3a ed.). Porto Alegre, RS: Capec.

Bicalho, P. P. G. (2005). Subjetividade e abordagem policial: por uma concepção de direitos humanos onde caibam mais humanos (Tese de doutorado). Universidade Federal do Rio de Janeiro, RJ.

Brasil. (1988). Constituição da República Federativa do Brasil. Dispõe sobre a segurança pública no país. Brasília, DF: Senado.

Cirilo, B. S. S. (2013). Resgate policial de reféns: uma forma de espetacularização da vida. Revista Epos, 4(2), Recuperado em: http://pepsic.bvsalud.org/pdf/epos/v4n2/07.pdf

Couto, G., Vandenberghe, L., \& Brito, E. A. G. (2012). Interações interpessoais e estresse entre policiais militares: um estudo correlacional. Arquivos Brasileiros de Psicologia, 64(2), 47-63. Recuperado de http://pepsic.bvsalud.org/ $\mathrm{pdf} / \mathrm{arbp} / \mathrm{v} 64 \mathrm{n} 2 / \mathrm{v} 64 \mathrm{n} 2 \mathrm{a} 05 . \mathrm{pdf}$

Dantas, M. A., Brito, D. V. C., Rodrigues, P. B., \& Maciente, T. S. (2010). Avaliação de estresse em policiais militares. Psicologia: Teoria e Prática, 12(3), 66-77. Recuperado de http://pepsic.bvsalud.org/pdf/ptp/v12n3/v12n3a06.pdf.

Derenusson, F. C., \& Jablonski, B. (2010). Sob fogo cruzado: o impacto do trabalho policial militar sobre a família do policial. Aletheia, (32), 22-37. Recuperado de http://pepsic.bvsalud.org/pdf/aletheia/n32/n32a03.pdf

Emilio, E. R. V. (2011). Impacto do conflito intragrupal, do suporte social no trabalho e do autoconceito profissional sobre a resiliência: um estudo com policiais militares (Dissertação de mestrado). Universidade Metodista de São Paulo, São Bernardo do Campo, SP.

Estado de São Paulo, O. (2012, 28 de dezembro). Em 11 meses, 106 policiais foram mortos por bandidos no Estado. Recuperado de http://www.estadao.com.br/noticias/impresso,em-11-meses-106-policiais-foram-mortos-por-bandidos-no-estado-,978309,0.htm

Faiad, C., Delabrida, Z. N., \& Nascimento, T. G. (2011). Survey sobre a avaliação da qualidade do serviço de segurança oferecido pela Polícia Militar segundo proprietários e funcionários de comércio em Brasília. Psicologia em Pesquisa. 5(1), 77-85. Recuperado de http://pepsic.bvsalud.org/pdf/psipesq/v5nl/v5nla09.pdf

Faria, D. G. R. (2000). O profissional de segurança pública: desempenho de seu papel num cenário stressante, de violência e de riscos: um estudo exploratório (Dissertação de mestrado). Instituto de Psicologia, Universidade de São Paulo, SP.

Faria, D. G. R. (2006). O profissional de segurança pública: papel social e identidade profissional (Tese de doutorado). Instituto de Psicologia, Universidade de São Paulo, SP.

Galvão, L. F. \& Serrano, C.E.G. (2007). Análise de discurso, leitura institucional: um método. In M. Guirado, \& R. Lerner, (Orgs.), Psicologia, pesquisa e clínica: por uma análise institucional do discurso (pp. 21-35). São Paulo, SP: Fapesp.

Globo.com (2015, 26 de agosto). Política. País tem 1 PM para cada 473 habitantes, diz IBGE. Recuperado de http:// g1.globo.com/politica/noticia/2015/08/pais-tem-1-pm-para-cada-473-habitantes-diz-ibge.html

Guirado, M. (2010). A análise institucional do discurso como analítica da subjetividade. São Paulo, SP: Annablume/FAPESP. 
Luciano, T. M. P. (2007). O uso da força não letal pela polícia nos encontros com o público (Dissertação de mestrado). Faculdade de Filosofia, Letras e Ciências Humanas, Universidade de São Paulo, SP.

Luciano, T. M. P. (2011). Treinamento policial: um meio de difusão de políticas públicas que incidem na conduta individual do policial de rua (Tese de doutorado). Faculdade de Filosofia, Letras e Ciências Humanas, Universidade de São Paulo, SP.

Oliveira, R. G. (2005). Uma experiência de plantão psicológico na Polícia Militar do Estado de São Paulo: reflexões sobre sofrimento e demanda (Dissertação de mestrado). Instituto de Psicologia, Universidade de São Paulo, SP.

Ribeiro, C. R. (2007). Sujeito-dobradiça: metáfora de subjetividade, metonímia institucional. In M. Guirado, \& R. Lerner, (Orgs.), Psicologia, pesquisa e clínica: por uma análise institucional do discurso (pp.245-262). São Paulo, SP: Fapesp.

Ribeiro, L. C. (2011). História das polícias militares no Brasil e da Brigada Militar no Rio Grande do Sul. In Anais do XXVI Simpósio Nacional de História - ANPUH. Recuperado de http://www.snh2011.anpuh.org/resources/ anais/14/1313022007_ARQUIVO_textoANPUH.pdf

São Paulo (Estado). (1989). Constituição do Estado de São Paulo. São Paulo: Assembléia Legislativa.

São Paulo (Estado). (2011b). Polícia Militar do Estado de São Paulo. Recuperado de http:/ /www.policiamilitar.sp.gov.br/

São Paulo (Estado). (2011a), Secretaria de Segurança Pública. Recuperado de http://www.ssp.sp.gov.br/institucional/

Silva, J. H. R. (2009). Estudo sobre o trabalho do policial e suas implicações na saúde mental (Dissertação de mestrado). Instituto de Psicologia, Universidade de São Paulo, SP.

Souza, J. L. C. \& Reis, J. F. G. (2014). A discricionariedade policial e os estereótipos suspeitos. Revista NUFEN, 6(1), 125-166. Recuperado de http://pepsic.bvsalud.org/pdf/rnufen/v6n1/a07.pdf

Spode, C.B. (2004). Ofício de Oficial, subjetividade e saúde mental na Polícia Militar (Dissertação de mestrado). Universidade Federal do Rio Grande do Sul, Porto Alegre, RS.

Universidade de São Paulo - USP (2013), Núcleo de Estudos da Violência [NEV]. Banco de dados. Recuperado de http://nevusp.org/banco-de-dados/

\section{Erika Ferreira de Azevedo}

Psicóloga, - Mestre em Ciências pelo Programa de Psicologia Escolar e Desenvolvimento do Instituto de Psicologia da Universidade de São Paulo. Psicóloga Educacional em clínica particular e Professora de Educação Especial da Escola Britânica de São Paulo.

E-mail: erikazevedo@gmail.com

Endereço para envio de correspondência:

Rua Tiagem, 251, apto. 24, Jaguaré. CEP: 05334-050

São Paulo - SP, Brasil.

Recebido 17/01/2015

Reformulação 22/05/2017

Aprovado 22/05/2017

Como citar: Azevedo, E. F. (2017). A polícia e suas polícias: clientela, hierarquia, soldado e bandido. Psicologia: Ciência e Profissão, 37(3), 553-564. https://doi.org/10.1590/1982-3703000192015

How to cite: Azevedo, E. F. (2017). The police and its polices: customers, hierarchy, soldier and criminal. Psicologia: Ciência e Profissão, 37(3), 553-564. https://doi.org/10.1590/1982-3703000192015

Cómo citar: Azevedo, E. F. (2017). La policía y sus policías: clientela, jerarquía, soldado y delincuente. Psicologia: Ciência e Profissão, 37(3), 553-564. https://doi.org/10.1590/1982-3703000192015 